ARTICLE

\title{
Assessing the Ageing Impact on Fatigue-Life of Asphalt Concrete
}

\section{Saad Issa Sarsam*}

Sarsam and Associates Consult Bureau SACB. Baghdad, Iraq

\begin{tabular}{l}
\hline ARTICLE INFO \\
\hline Article history \\
Received: 11 January 2021 \\
Accepted: 2 March 2021 \\
Published Online: 30 March 2021
\end{tabular}

Keywords:

Fatigue life

Asphalt concrete

Flexure strain

Ageing

Temperature

Strain level

\section{Introduction}

One of the important parameters for the structural design of asphalt concrete pavements is the assessment of fatigue-life of the asphalt concrete mixture, which can be determined by implementing cyclic-fatigue tests in the laboratory. Golchin and Mansourian ${ }^{[1]}$ evaluated fatigue properties and fatigue-life of asphalt concrete mixtures by implementing the four-point bending-beam test. Analysis of the tests results showed that the mixtures tested at lower strain levels, had higher final stiffness while the-fatigue life of specimens increased when the level of testing strains decreased. Song-tao et al. ${ }^{[2]}$ stated that the problems of asphalt aging have not been comprehensively considered

\begin{abstract}
The fatigue-life of asphalt concrete is often related to environmental condition, loading condition, ageing, material composition and properties. This work investigates the influence of short and long term ageing of laboratory beam specimens, asphalt percent, and testing temperature on fatigue life of asphalt concrete wearing course. Slab samples of ( $30 \times 40$ x 6$) \mathrm{cm}$ have been prepared, beam specimens of $(40 \times 5 \times 6) \mathrm{cm}$ were extracted from the asphalt concrete slab samples and tested for fatigue-life under the impact of three levels of micro strain $(250,400$, and [3] 750) at $(5,20$, and 30$){ }^{\circ} \mathrm{C}$ before and after practicing long-term aging. It was observed that the fatigue-life decreased by ( 85 and 97$) \%$, (87.5 and 97.4) \%, (71.4 and 95.2) \% after increasing the applied microstrain from (250 to 400 and 750) $\mu \varepsilon$ for control mixture and for mixtures subjected to shortand long-term ageing processes respectively. The fatigue-life increased by (142.8 and 257.1$) \%$, (34.4 and 57.8$) \%$ and (10 and 30$) \%$ when the asphalt content increased from (4.4 to 4.9 and 5.4 ) \% for specimens practicing the applied microstrain of $(250,400$ and 750$) \mu \varepsilon$ respectively. It can be concluded that the fatigue life increases by a range of (two to fifteen) folds when the testing temperature increases from (5 to 20 and $30)^{\circ} \mathrm{C}$ respectively.
\end{abstract}

when pavement is designed globally, so the effects of aging on the life of asphalt pavement have not been studied accurately. The study of fatigue performance in different degrees of aging plays a significant role in improving design parameters and asphalt mixtures, and preventing early damage, as well as improving road performance and extending the life of asphalt pavement. Aging process of asphalt binder occurs in three stages: the first stage occures very fast during the production process of asphalt mixtures. Such stage is referred to as short-term aging process. The second stage of binder aging occurs at a slower rate during the transportation of the mixtures to the laying site, laying down and compaction of the mixture. The third stage occurs after construction while the asphalt concrete is in service

*Corresponding Author:

Saad Issa Sarsam,

Sarsam and Associates Consult Bureau SACB. Baghdad, Iraq;

Email: saadisasarsam@coeng.uobaghdad.edu.iq 
and exposed to the surrounding environment as reported by Glover et al. ${ }^{[3]}$. Paul et al. ${ }^{[4]}$ stated that aging of asphalt concrete continues for two to three years until the mixture approaches to its maximum density, and no further densification may occur. Aging can affect the physical properties of asphalt concrete mixture significantly, and hence affecting the performance of the asphalt pavement. However, it is required to characterize the aged asphalt mixture properly for achieving the successful design of asphalt pavements. A study by Al-Khateeb and Alqudahaims ${ }^{[5]}$ investigated the impact of laboratory aging on the fatigue-life performance of asphalt mixtures. The mixtures were subjected to short and long term ageing then tested for fatigue using indirect tensile and various initial strain levels. It was found that the short term ageing led to an increase in fatigue-life. Findings also showed that the fatigue-life increased as the testing temperature increase. The evolution of permanent strain, fatigue-life, and resilient modulus of an asphaltic concrete mixture exposed under weather conditions was investigated by Quintana and Lizcano ${ }^{[6]}$. It was concluded that resilient modulus of the asphalt mixtures increases by more than two folds during 48 months of continuous exposure under the test environmental conditions. Such stiffness increase exhibits an increment of approximately ten folds in the mixture fatigue-life because of the binder stiffening effect due to its own ageing condition. The effect of ageing and temperature on the fatigue-life of asphalt concrete specimens made with two binder types, was studied by López-Montero and Miró ${ }^{[7]}$. Specimens have practiced an accelerated laboratory-ageing process, then were tested by using the strain sweep test at different testing temperatures of $(-5,5$ and 20$){ }^{\circ} \mathrm{C}$. Test results were compared with those obtained from the un-aged specimens, it is showing the relative importance of ageing and temperature on the parameters which determine the fatigue-life of the asphalt mixture. The asphalt concrete mixtures behaviour becomes more brittle after practicing ageing process and the reduction of testing temperature. However, ageing process can hardly has an effect on fatigue-life at lower temperatures. As reported by Sol-Sánchez et al. ${ }^{[8]}$, bituminous mixtures are designed and manufactured to withstand the traffic loads imposed, and also to resist the action of the environment. It was reported that it is necessary to carefully investigate all the variables that influence ageing. In fact, the ageing of asphalt concrete mixtures depends on multiple factors, such as air temperature, and availability of rain water, which therefore can have a great influence on the durability of asphalt mixtures. Sarsam ${ }^{[9]}$ studied the impact of ageing on the stiffness of asphalt concrete beam specimens through the fatigue process. It was concluded that the stiffness is susceptible to moisture damage and aging, the increase in
Microstrain level leads to a remarkable reduction in initial and failure stiffness's. The stiffness is susceptible to the testing temperature and asphalt content, lower testing temperature of $5^{\circ} \mathrm{C}$ exhibits higher stiffness value, while higher binder content has a negative impact on the stiffness. The effect of aging process on the fatigue properties of polymer-modified asphalt mixtures were assessed by Zhu et al. ${ }^{[10]}$. Two kinds of aging techniques were adopted, the first one is the short-time aging, while the second one is the natural-aging of the original specimen as exposed in the sunlight, and subjected to the rain and temperature changes for three, six, and nine months. Four-Point Bending beam test was conducted on the specimens to evaluate the fatigue-life properties of aged-asphalt mixtures at $15^{\circ} \mathrm{C}$ and the test results were compared with the original specimens. Test results indicated that the fatigue-life of aged-specimen decreases significantly when it was compared with the original ones, especially of the natural-aged specimens. Miró et al. ${ }^{[11]}$ examined the combined influence of the loss of volatiles from the binder and the oxidation produced during the ageing process on the fatigue behaviour of the bitumen. Different temperatures have been implemented for evaluating the effect of visco-elastic phenomena on aged binder fatigue. The test results showed that the testing-temperature plays an important role in the influence of ageing on the fatigue response of bituminous binders, and in the mechanical response of these materials. Sarsam and AL-Lamy ${ }^{[12]}$ stated that fatigue-life is the process of cumulative damage of asphalt pavement and it is one of the major causes of cracking. The traditional fatigue-life approach states that damage may occur in asphalt concrete specimen after practicing dynamic-repetitive loading which leads to fatiguefailure of the specimen. The number of load repetitions to failure equal to the fatigue-life, and can be calculated based on stress, or strain. The results of repeated four-point flexural-fatigue beam testing conducted by Sarsam and Alwan ${ }^{[13]}$ have indicated that fatigue-life decreased by 70 percent after subjecting the asphalt concrete specimens to moisture damage process. For a Microstrain range from (250 to 400), the fatigue-life decreased by 87 percent as compared to reference mixture. Karakas ${ }^{[14]}$ stated that exposure of asphalt pavement to environmental-conditions such as traffic and climate is one of the prominent ageing reasons for asphalt binder. The common mechanism of binder aging is the chemical-degradation in the structure of the binder by oxidation. Aging of asphalt binder can cause several serious distress issues of the asphalt pavement such as stiffening and stripping which may accelerates the formation of fatigue-cracking, and moisture-induced damage problems such as raveling, and potholes. The aim of the present investigation is to assess the impact of short and long term 
ageing process, testing temperature, asphalt content, and strain levels on the fatigue-life of asphalt concrete wearing course by implementing the repeated four-point flexure test.

\section{Materials Properties and Testing Methods}

The materials implemented in the present assessment are economicaly available, and usually used by roadway agencies for asphalt pavement construction in Iraq.

\subsection{Asphalt Cement}

Asphalt binder with penetration graded of (40-50) was utilized in this assessment. It is obtained from AL-Naesria oil Refinery. The properties of asphalt cement comply with the SCRB ${ }^{[15]}$ requirements. The physical properties of the asphalt binder are presented in Table 1.

Table 1. Physical Properties of Asphalt Binder

\begin{tabular}{|c|c|c|c|c|}
\hline Property & Test Conditions & $\begin{array}{c}\text { ASTM }{ }^{[16]} \text { Desig- } \\
\text { nation }\end{array}$ & Value & SCRB $^{[15]}$ \\
\hline $\begin{array}{l}\text { Penetration }(0.1 \\
\mathrm{mm})\end{array}$ & $\begin{array}{c}25^{\circ} \mathrm{C}, 100 \mathrm{gm}, 5 \\
\text { seconds }\end{array}$ & D5-06 & 42 & $40-50$ \\
\hline $\begin{array}{c}\text { Softening Point } \\
\left({ }^{\circ} \mathrm{C}\right)\end{array}$ & (Ring and Ball) & D36-895 & 49 & - \\
\hline Ductility $(\mathrm{Cm})$ & $\begin{array}{c}25^{\circ} \mathrm{C}, 5 \mathrm{Cm} / \mathrm{min}- \\
\text { utes }\end{array}$ & D113-99 & 136 & $>100$ \\
\hline Specific Gravity & $25^{\circ} \mathrm{C}$ & $\mathrm{D} 70$ & 1.04 & - \\
\hline Flash Point $\left({ }^{\circ} \mathrm{C}\right)$ & $\begin{array}{l}\text { Cleaveland open } \\
\text { cup }\end{array}$ & D92-05 & 256 & $>232$ \\
\hline \multicolumn{5}{|c|}{ Properties After Thin Film Oven Test as per D1754-97 } \\
\hline $\begin{array}{c}\text { Penetration } \\
(0.1 \mathrm{~mm})\end{array}$ & $\begin{array}{c}25^{\circ} \mathrm{C}, 100 \mathrm{gm}, 5 \\
\text { seconds }\end{array}$ & D5-06 & 33 & $<55 \%$ \\
\hline Ductility $(\mathrm{Cm})$ & $\begin{array}{c}25^{\circ} \mathrm{C}, 5 \mathrm{Cm} / \mathrm{min}- \\
\text { utes }\end{array}$ & D113-99 & 83 & $>25 \%$ \\
\hline
\end{tabular}

\subsection{Fine and Coarse Aggregates}

Crushed coarse aggregates (passing sieve size 19 $\mathrm{mm}$ and retained on sieve No. 4) was brought from AL-Ukhaider quarry. A mixture of natural and crushed sand was implemented as fine aggregates (particle passing sieve No. 4 and retained on sieve No.200) as per SCRB ${ }^{[15]}$ specification. The sand was brought from the same source. The physical properties of fine and coarse aggregates are demonstrated in Table 2.

Table 2. Physical Properties of Fine and Coarse Aggregates

\begin{tabular}{ccccc}
\hline Property & $\begin{array}{c}\text { Coarse } \\
\text { aggregates }\end{array}$ & $\begin{array}{c}\text { ASTM } \\
\text { Designa- } \\
\text { tion }\end{array}$ & $\begin{array}{c}\text { Fine ag- } \\
\text { gregates }\end{array}$ & $\begin{array}{c}\text { ASTM } \\
\text { Designa- } \\
\text { tion }\end{array}$ \\
\hline Bulk Specific Gravity & 2.542 & $\mathrm{C} 127-01$ & 2.558 & $\mathrm{C} 128-01$ \\
$\begin{array}{c}\text { Percent Water Absorption } \\
\text { Percent Wear (Los Angeles } \\
\text { abrasion Test) }\end{array}$ & $1.07 \%$ & $\mathrm{C} 127-01$ & $1.83 \%$ & $\mathrm{C} 128-01$ \\
\hline
\end{tabular}

\subsection{Mineral Filler}

The mineral filler implemented in the present work is the limestone dust, it is mostly passing sieve No.200. It was brought from Karbala governorate. The physical properties of the mineral filler are exhibited in Table 3.

Table 3. Physical Properties of the Mineral Filler

\begin{tabular}{|c|c|c|}
\hline \multirow{2}{*}{ Property } & Bulk Specific Gravity & Percent Passing Sieve No. 200 \\
\cline { 2 - 3 } & 2.617 & 94 \\
\hline
\end{tabular}

\subsection{Selection of Aggregates Gradation}

The selected aggregates gradation in this assessment follows the wearing course requirement as per SCRB ${ }^{[15]}$ specification. It has a nominal maximum size of (12.5 $\mathrm{mm})$. Table 4 shows the implemented aggregates gradation.

Table 4. Implemented Gradation for Combined Aggregates

\begin{tabular}{ccc}
\hline \multirow{2}{*}{ Sieve size $(\mathbf{m m})$} & \multicolumn{2}{c}{ Passing by weight\% } \\
\cline { 2 - 3 } & Selected Gradation & SCRB ${ }^{[15]}$ Specification \\
\hline 19 & 100 & 100 \\
12.5 & 95 & $90-100$ \\
9.5 & 83 & $76-90$ \\
4.75 & 59 & $44-74$ \\
2.36 & 43 & $25-58$ \\
0.3 & 13 & $5-21$ \\
0.075 & 7 & $4-10$ \\
\hline
\end{tabular}

\subsection{Preparation of the Asphalt Concrete Mixture}

Aggregates were subjected to oven drying to a constant weight at $110^{\circ} \mathrm{C}$, and then sieved to different sizes and each size was separately stored. Fine and coarse aggregates were recombined with the specific percentage of mineral filler to meet the SCRB ${ }^{[15]}$ specifications. The combined aggregates were then heated to $160^{\circ} \mathrm{C}$, while the asphalt binder was separately heated to a temperature of $150^{\circ} \mathrm{C}$. The desired amount of Asphalt binder was added to the heated aggregates and mixed thoroughly using a mechanical mixer for three minutes until all aggregate particles were coated with a thin film of asphalt binder. The asphalt concrete mixture was subjected to short-term oven aging for four hours at a temperature of $135^{\circ} \mathrm{C}$ as per AASHTO ${ }^{[17]}$. Asphalt concrete mixtures were prepared at optimum asphalt content of $4.9 \%$ and 
at asphalt contents of 0.5 percent below and above the optimum, (4.4 and 5.4) \%. The process of finding the optimum asphalt content was based on Marshall Properties as per AASHTO ${ }^{[17]}$, the details could be found at Sarsam and Alwan ${ }^{[13]}$. Slab samples of $(400 \times 300 \times 60) \mathrm{mm}$ were prepared using the rolling compaction technique to the target bulk density according to EN12697-33 ${ }^{[18]}$. Beam specimens of $(5 \times 6 \times 40) \mathrm{cm}$ sizes were extruded from the slab using the diamond saw. Beam specimens were conditioned to long-term aging as per AASHTO ${ }^{[19]}$ procedure. Figure 1 exhibits the long-term ageing process.

\subsection{Determination of Fatigue Life with the Aid of Repeated Flexural Beam-Fatigue Test}

The repeated-flexural beam fatigue test was implemented on the beam specimens as per AASHTO T 321 ${ }^{[20]}$. Asphalt concrete beams were placed in the four-point loading apparatus. Three testing temperatures of $(30,20$, and 5) ${ }^{\circ} \mathrm{C}$ have been implemented. On the other hand, three different Microstrain levels of 250, 400, and 750 were tried to simulate various modes of loading in the field. The flexural-fatigue test is performed by placing the asphalt concrete beam specimen in the repetitive four-points loading chamber and application of specified strain level and testing temperature. Throughout the test, the beam was held in place by four clamps and the repeated sinusoidal load was applied to the two inner clamps with the outer clamps providing a reaction load. Such setup provides a constant bending moment over the central portion of the beam between the two inside clamps. The number of load cycles to failure was then recorded which gave an estimation of a particular mixture's fatigue-life. Figure 2 exhibits the four-point bending beam test setup.

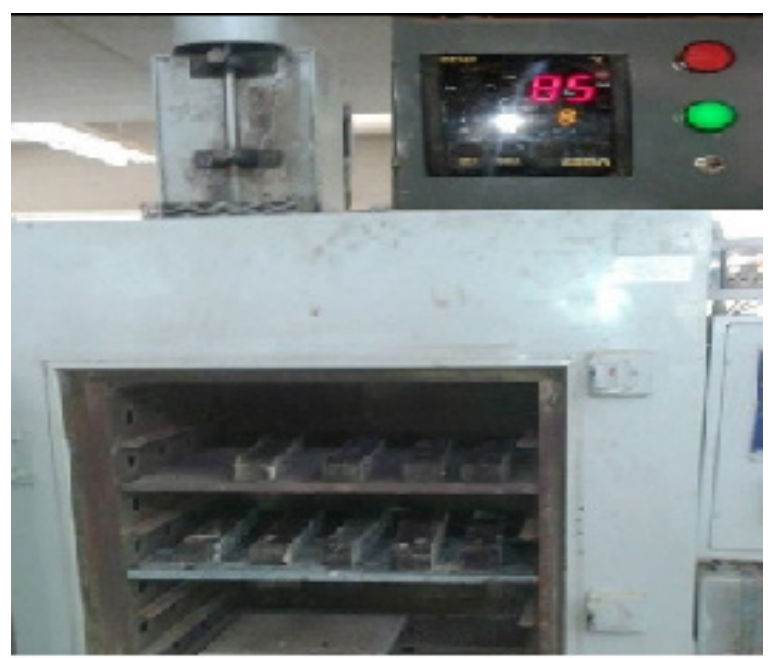

Figure 1. Long-term ageing process

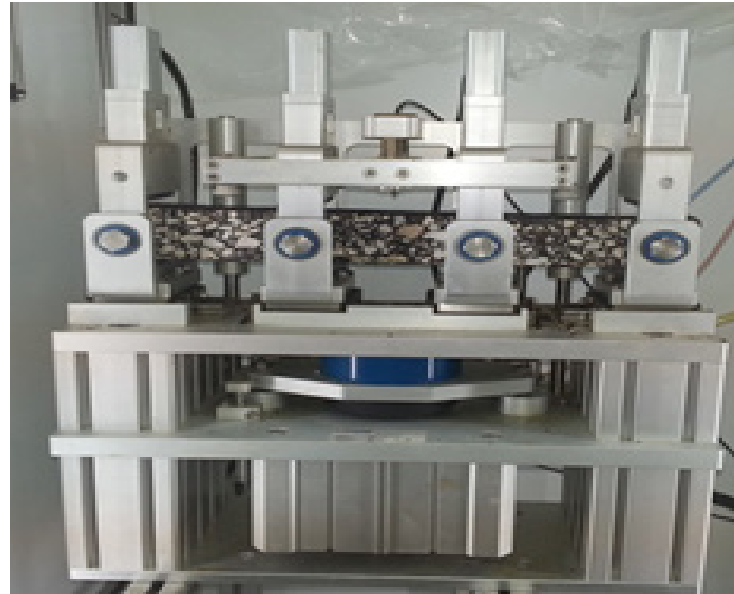

Figure 2. Four-point bending beam test setup

\section{Discussions on Test Results}

\subsection{Evaluation of Fatigue-Life}

Fatigue-life measurements were conducted at microstrain levels of 750,400 , and 250 , a frequency level of $5 \mathrm{~Hz}$, testing temperature of $(5,20 \text {, and } 30)^{\circ} \mathrm{C}$, and three percentages of asphalt contents. Log-log Plots were established between the fatigue life $(\mathrm{Nf})$ and the above-mentioned variables. The most important parameters for fatigue life assessment are the intercept, and the slope of the fatigue-life curve. The prepared asphalt concrete mixture was separated to three lots. The first lot was denoted as the control mixtures. The control mixture was compacted in the roller compactor and a slab sample was obtained. Beam specimens were extracted from the slabs and tested for fatigue life. The second lot had practiced the shortterm ageing as per AASHTO ${ }^{[19]}$ procedure, then it was compacted to slab samples. Beam specimens were extracted from the slabs of the second lot and tested for fatigue life. The third lot was subjected to short term ageing, and then it was compacted to slab samples. Beam specimens were extracted from the slabs of the third lot and subjected to long-term ageing as per AASHTO ${ }^{[20]}$, then tested for fatigue life.

\subsection{Influence of Ageing on Fatigue-Life for As- phalt Concrete}

The fatigue life of asphalt concrete was evaluated by implementing the repeated-flexural beam-fatigue test on the beam specimens as per AASHTO T $321^{[20]}$. Figure 3 demonstrate the influence of ageing process on the fatigue-life. It can be observed that the fatigue-life decreases for asphalt concrete after practicing the ageing process regardless of the ageing technique implemented. 
When the applied microstrain level was low $(250 \mu \varepsilon)$, the fatigue-life decreases by (16.4 and 77.5$) \%$ after practicing short- and long-term ageing respectively. When the applied microstrain level was moderate $(400 \mu \varepsilon)$, the fatigue-life decreases by (30.3 and 57) \% after practicing short- and long-term ageing respectively. However, after application of high level of microstrain $(750 \mu \varepsilon)$, the reduction in fatigue-life was (31.4 and 65.5) \% after practicing short- and long-term ageing respectively.

However, the fatigue-life decreases by ( 85 and 97) $\%$, (87.5 and 97.4) \%, (71.4 and 95.2) \% after increasing the applied microstrain from (250 to 400 and 750$) \mu \varepsilon$ for control mixture and for mixtures subjected to short-and long-term ageing processes respectively. Similar findings are addressed by Zhu et al. ${ }^{[10]}$.

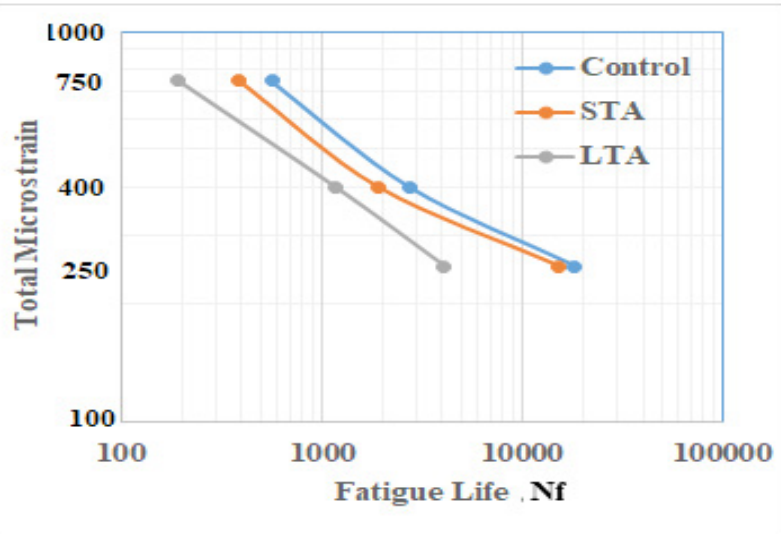

Figure 3. Influence of ageing process on the fatigue-life

Table 5 exhibits the fatigue-life parameters of asphalt concrete, the ageing process was able to decrease both intercepts which represent the total microstrain after the first load repetition $(\mathrm{N}=1)$, and the slope which represent the rate of deformation throughout the fatigue-life. Such observation indicates the stiffening of asphalt concrete after the ageing process. The power models relating the microstrain $(\mu \varepsilon)$ with the fatigue-life $(\mathrm{Nf})$ exhibit a strong coefficient of determination $\left(R^{2}\right)$. Similar findings were reported by Sarsam and Alwan ${ }^{[2]}$.

Table 5. Fatigue Parameters and Models for Asphalt Concrete Under Ageing

\begin{tabular}{|c|c|c|c|c|c|}
\hline \multirow{2}{*}{$\mathrm{AC} \%$} & \multirow{2}{*}{ State } & \multicolumn{2}{|c|}{$\begin{array}{c}\text { Fatigue Parame- } \\
\text { ter }\end{array}$} & \multirow{2}{*}{ Models } & \multirow{2}{*}{$\begin{array}{c}\text { Coefficient of } \\
\text { Determination } R^{2}\end{array}$} \\
\hline & & Slope & Intercept & & \\
\hline \multirow{3}{*}{$4.9 \%$} & Control mix & 0.314 & 5214.3 & $\begin{array}{c}\mu \varepsilon=5214.3 \\
\mathrm{Nf}^{-0.31} 4\end{array}$ & 0.981 \\
\hline & $\begin{array}{l}\text { Short term } \\
\text { Ageing }\end{array}$ & 0.295 & 4113 & $\mu \varepsilon=\underset{-0.295}{4113 \mathrm{Nf}}$ & 0.974 \\
\hline & $\begin{array}{l}\text { Long term } \\
\text { Ageing }\end{array}$ & 0.360 & 5015.3 & $\begin{array}{c}\mu \varepsilon=5015.3 \\
N f^{-0.36}\end{array}$ & 0.998 \\
\hline
\end{tabular}

\subsection{Influence of Asphalt Binder on Fatigue-Life for Asphalt Concrete}

Figure 4 depicts the influence of asphalt cement content on fatigue-life of asphalt concrete. It can be observed that the fatigue-life increases significantly as the binder content increases regardless of the applied microstrain. This could be attributed to the increase in asphalt cement film thickness which can possess a more durable mixture. It can be detected that at low microstrain level of $(250 \mu \varepsilon)$, the fatigue-life increased by $(142.8,257.1) \%$ when the asphalt binder content increased from (4.4 to 4.9 and 5.4) \%. When the applied microstrain level was moderate $(400 \mu \varepsilon)$, the fatigue-life increased by (34.4 and 57.8) \% when the asphalt binder content increased from (4.4 to 4.9 and 5.4) \%. However, after application of high level of microstrain $(750 \mu \varepsilon)$, the improvement in fatigue-life was minimal in a range of (10-30) \% as the asphalt content increases.

Table 6 exhibits the fatigue parameters of asphalt concrete at various asphalt percentages, increment of asphalt content was able to decrease both intercept and the slope, thus improving the flexibility of asphalt concrete. The power models relating the microstrain $(\mu \varepsilon)$ with the fatigue life (Nf) at various binder content exhibit a strong coefficient of determination $\left(\mathrm{R}^{2}\right)$. Similar findings have been reported by Sarsam and AL- Lamy ${ }^{[22]}$.

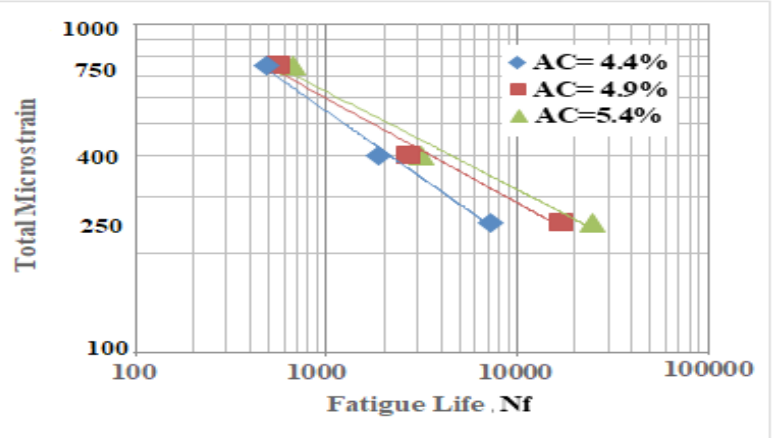

Figure 4. Influence of Asphalt Binder on the fatigue-life

Table 6. Fatigue Parameters and Models for Asphalt Concrete at Various Binder Content

\begin{tabular}{ccccc}
\hline Asphalt Content \% & Intercept & Slope & Models & $\mathbf{R}^{2}$ \\
\hline 4.4 & 9065.3 & 0.407 & $\mu \mathcal{E}=9065.3(\mathrm{Nf})^{-0.407}$ & 0.993 \\
4.9 & 5424.7 & 0.319 & $\mu \mathcal{E}=5424.7(\mathrm{Nf})^{-0.319}$ & 0.983 \\
5.4 & 4984 & 0.300 & $\mu \mathcal{E}=4984(\mathrm{Nf})^{-0.3}$ & 0.973 \\
\hline
\end{tabular}

\subsection{Influence of Testing Temperatures on the Fa- tigue-Life for Asphalt Concrete}

Figure 5 exhibits the influence of testing temperatures on the fatigue-life of asphalt concrete. It can be observed 
that the mixture exhibits low fatigue-life when tested at cold environment of $5^{\circ} \mathrm{C}$ as compared to the warmer environment. This may be attributed to the stiffer condition of the mixture and higher viscosity of the binder. A steep shape of the fatigue-life-microstrain relationship could be detected indicating lower fatigue life and possible brittle and fracture type of failure. On the other hand, the fatigue-life increases significantly as the testing temperature increases regardless of the applied microstrain. For specimens practicing high microstrain level of $(750 \mu \varepsilon)$, the fatigue life increased by (112.4, and 253.2) \% when the testing temperature rises from (5 to 20 and 30 ) ${ }^{\circ} \mathrm{C}$ respectively. When the asphalt concrete beam specimens were practicing moderate level of microstrain of (400 $\mu \varepsilon)$, the fatigue life increased by (480.3, and 1370.5$) \%$ when the testing temperature rises from (5 to 20 and 30) ${ }^{\circ} \mathrm{C}$ respectively. However, specimens subjected to low microstrain level of $(250 \mu \varepsilon)$ exhibit an increment in fatigue-life of (1316, and 1588.3 ) \% when the testing temperature rises from (5 to 20 and 30$){ }^{\circ} \mathrm{C}$ respectively. Such behavior agrees with López-Montero and Miró ${ }^{[7]}$.

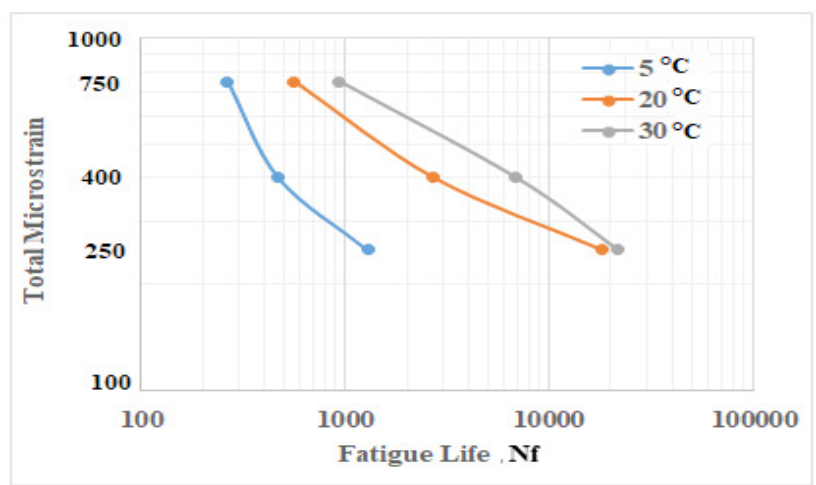

Figure 5. Impact of Testing Temperature on the fatigue-life

Table 7 exhibits the fatigue parameters of asphalt concrete at various testing temperature, it can be noted that increment of testing temperature was able to increase the intercept and decreases the slope, thus exhibiting more flexibility of asphalt concrete. The power models relating the microstrain $(\mu \varepsilon)$ with the fatigue life (Nf) at various testing temperatures exhibit a strong coefficient of determination $\left(\mathrm{R}^{2}\right)$. Similar findings were reported by Quintana and Lizcano ${ }^{[6]}$.

Table 7. Fatigue Parameters and Models for Asphalt Concrete at Various Testing Temperature

\begin{tabular}{ccccc}
\hline Testing Temperature ${ }^{\circ} \mathbf{C}$ & Intercept & Slope & Models & $\mathbf{R}^{2}$ \\
\hline 5 & 28492 & 0.669 & $\mu \varepsilon=28492(\mathrm{Nf})^{-0.669}$ & 0.942 \\
20 & 5214.3 & 0.314 & $\mu \varepsilon=5214.3(\mathrm{Nf})^{-0.314}$ & 0.981 \\
30 & 8108.4 & 0.346 & $\mu \varepsilon=8108.4(\mathrm{Nf})^{-0.346}$ & 0.994 \\
\hline
\end{tabular}

\section{Conclusions}

According to the testing program and limitations of materials, the conclusions which can be drawn are listed below.

The fatigue-life decreases by ( 85 and 97$) \%,(87.5$ and $97.4) \%$, and (71.4 and 95.2) \% after increasing the applied microstrain from (250 to 400 and 750) $\mu \varepsilon$ for control mixture and for mixtures subjected to short-and long-term ageing processes respectively.

The fatigue-life increased by (142.8 and 257.1) \%, (34.4 and 57.8) \% and (10 and 30) \%when the asphalt content increased from $4.4 \%$ to (4.9 and 5.4) \% for specimens practicing the applied microstrain of $(250,400$ and 750$)$ $\mu \varepsilon$ respectively.

The fatigue-life increases by a range of (two to fifteen) folds when the testing temperature increased from ( 5 to 20 and 30$)^{\circ} \mathrm{C}$ respectively.

The developed models could be implemented for prediction of the fatigue-life for asphalt concrete under the assessed conditions.

\section{References}

[1] Golchin B. and Mansourian A. (2017). Evaluation of Fatigue Properties of Asphalt Mixtures Containing Reclaimed Asphalt Using Response Surface Method. International Journal of Transportation Engineering, Vol.4, No.4, P. 335-350. Spring.

[2] Song-tao L., Zhaohui L., Juan X. (2015). Fatigue performance of aging asphalt mixtures. Polimery 2015, Vol. 60, No. 2. P. 126-131. Doi: dx.doi.org/10.14314/ Polimery. 126.

[3] Glover C. J., Epps Martin E., Chowdhury A., Han R., Prapaitrakul N., Jin X. and Lawrence J. (2009). Evaluation of Binder Aging and Its Influence in Aging of Hot Mix Asphalt Concrete: Literature Review and Experimental Design, Research Report No. FHWA/ TX-08/0-6009-1, Texas Transportation Institute, College Station, Texas.

[4] Paul D. K., Sirin O., Kassem E. (2016). Laboratory investigation of asphalt mixture aging. Proceedings, E\&E Congress 6th Eurasphalt \& Eurobitume Congress, 1-3 June, Prague, Czech Republic.

[5] Al-Khateeb G. and Alqudah O. (2018). Effect of Short-Term and Long-Term Aging on Fatigue Performance of Superpave Hot-Mix Asphalt (HMA). Jordan Journal of Civil Engineering, Volume 12, No. 4. P 580-589.

[6] Quintana H. and Lizcano F. (2012). Evaluation of mechanical parameters of an asphalt mixture under the environmental conditions of Bogotá D.C. Revista 
Ingeniería de Construcción Vol. 27 No1, Abril de 2 www.ricuc.cl.

[7] López-Montero T. and Miró R. (2017). Ageing and temperature effect on the fatigue performance of bituminous mixtures. Materiales de Construcc ión Vol. 67, Issue 327, July-September, e126 http://dx.doi. org/10.3989/mc.2017.04216.

[8] Sol-Sánchez, M.; Moreno-Navarro, F.; García-Travé, G.; Rubio-Gámez, M.C. (2015) Laboratory study of the long-term climatic deterioration of asphalt mixtures. Constr. Build. Mater.88, pp. 32-40. http:// dx.doi.org/10.1016/j. conbuildmat.2015.03.090.

[9] Sarsam S. I. (2016). Influence of Aging, Temperature and Moisture Damage on the Stiffness of Asphalt Concrete through the Fatigue Process. International Journal of Scientific Research in Knowledge, 4(4), pp. 077-084. http://dx.doi.org/10.12983/ijsrk-2016-p0077-0084.

[10] Zhu G. J., Wu S. P., Liu R., Zhou L. (2009). Study on the Fatigue Property for Aged Asphalt Mixtures by Using Four Point Bending Tests. Materials Science Forum (Volume 614), March. P. 289-294. https://doi. org/10.4028/www.scientific.net/MSF.614.289.

[11] Miró R., Martínez A., Moreno-Navarro F., Rubio-Gámez M. (2015). Effect of ageing and temperature on the fatigue behavior of bitumen's. Materials \& Design, Volume 86, 5 December, P. 129-137. https://doi. org/10.1016/j.matdes.2015.07.076.

[12] Sarsam S. I., AL-Lamy A. K. (2016). Fatigue Behavior of Modified Asphalt Concrete Pavement, Journal of Engineering, 22 (2).

[13] Sarsam S. I., Alwan A. H. (2014). Assessing Fatigue Life of Super pave Asphalt Concrete, American Journal of Civil and Structural Engineering AJCSE 2014, Sciknow Publication, 1(4), pp. 88-95.

[14] Karakas A. S. (2018). Aging Effects on Mechanical
Characteristics of Multi- Layer Asphalt Structure. Provisional chapter. http://dx.doi.org/10.5772/intechopen. 75698.

[15] SCRB. (2003). State Commission of Roads and Bridges. Standard Specification for Roads \& Bridges, Ministry of Housing \& Construction, Iraq.

[16] ASTM. (2015). American Society for Testing and Materials. Road and Paving Material, Vehicle-Pavement System, Annual Book of ASTM Standards, Vol.04.03.

[17] AASHTO. (2013). Standard Specification for Transportation Materials and Methods of Sampling and Testing, American Association of State Highway and Transportation Officials, 14th Edition, Part II, Washington, D.C.

[18] . EN 12697-33. (2007). Bituminous Mixtures - Test Methods for Hot Mix Asphalt - part 33: Specimen prepared by Roller Compactor, European Committee for Standardization.

[19] AASHTO. (2013). Standard Practice for Mixture Conditioning of Hot Mix Asphalt (HMA). R30 AASHTO Provisional Standards, American Association of State Highway and Transportation Officials, Washington, D.C.

[20] AASHTO T-321. (2010). Method for Determining the Fatigue Life of Compacted Hot-Mix Asphalt (HMA) Subjected to Repeated Flexural Bending, AASHTO Provisional Standards.

[21] Sarsam S..I, and Alwan A. H. (2014). Impact of Aging on Shear, Tensile Strength and Permanent Deformation of Super pave Asphalt Concrete, International Journal of Scientific Research in Knowledge, 2(10): 487-496.

[22] Sarsam S. I. and AL-Lamy A. K. (2016). Fatigue Behavior of Modified Asphalt Concrete Pavement. Journal of Engineering, Vol. 22 No. 2, February. 